\title{
INOVASI KURIKULUM PAI SEBAGAI PROGRAM DERADIKALISASI
}

\author{
AyubBahruddin, ${ }^{1}$ Sri Wahyuni, ${ }^{2}$ Tasara Amida Ardian Sari,${ }^{3}$ \\ Yusuf Arsyad Wahid Tajuddin, ${ }^{4}$ Zakiyyatur Rohmah ${ }^{5}$ \\ Institut Agama Islam Negeri Ponorogo, Jawa Timur \\ Email : Ayubbahrudin007@gmail.com ${ }^{2}$ Wahyuni24klt@gmail.com ${ }^{3}$ Tasaraardian1505@gmail.com ${ }^{4}$ \\ Yusufarsyad1927@gmail.com ${ }^{5}$ Zakiyya20.rohmah@gmail.com ${ }^{6}$
}

DOI: https:// doi.org/10.37758/jat.v3i1.192

\begin{tabular}{l|l|l} 
Received: Maret 2020 & Accepted: Juni 2020 & Published: Juni 2020
\end{tabular}

\begin{abstract}
:
Radical action is a serious problem facing the Indonesian people. This case cannot be separated from the lack of public attention to religious education Coupled with the role of the government which pays little attention to the Islamic Religious Education system for schools in Indonesia. Islamic Education that fosters moderate character can be a solution to this problem. Therefore the purpose of this study is to explain how Islamic Religious Education plays a role in deradicalization and how PAI's curriculum innovations can produce people of moderate character. This research is a literature research using content analysis. The conclusion of this research is that first, Islamic Education can play a role in deradicalization through material content, the Teacher's thinking style and teacher's guidance to students. Secondly, curriculum innovation to form moderate character can be done by giving a load of tolerance values and patriotism, creating teachers with an inclusive paradigm, implementing learning in a creative and actual way.
\end{abstract}

Key words : Curriculum Innovation, Deradicalization, Tolerance, Islamic Education.

\begin{abstract}
Abstrak:
Tindakan radikal merupakan masalah serius yang dihadapi bangsa Indonesia.Kasus ini tidak lepas dari kurangnya perhatian publik terhadap pendidikan agama Ditambah dengan peran pemerintah yang kurang memperhatikan sistem Pendidikan Agama Islam untuk sekolah-sekolah di Indonesia.Pendidikan Agama Islam yang menumbuhkan karakter moderat dapat menjadi solusi terhadap permasalahan tersebut.Maka dari itu tujuan dari penelitian ini adalah untuk menjelaskan bagaimana Pendidikan Agama Islam berperan dalam deradikalisasi dan bagaimana inovasi kurikulum PAI yang dapat menghasilkan manusia yang berkarakter moderat.Penelitian ini merupakan penelitian literatur dengan menggunakan analisis isi. Kesimpulan penelitian ini adalah pertama, Pendidikan Agama Islam dapat berperan dalam deradikalisasi melalui muatan materi, corak berpikir Guru dan pembinaan guru terhadap siswa. Kedua, inovasi kurikulum untuk membentuk karakter moderat yang dapat dilakukan dengan cara memberikan muatan nilai toleransi dan cinta tanah air, menciptakan guru yang berparadigma inklusif, melaksanakan pembelajaran dengan kreatif dan aktual.
\end{abstract}

Kata Kunci : Inovasi Kurikulum, Deradikalisasi, Toleransi, Pendidkan Agama Islam. 


\section{PENDAHULUAN}

Permasalahan mengenai radikalisme merupakan permaslaahan besar bangsa Indonesia.Permasalahan ini tidak dating begitu saja namun ada penyebabnya.Semakin beragamnya masyarakat atau pluralnya kehidupan beragama merupakan salah satu penyebabnya.Fenomena tersebut tidak jadi masalah jika dibarengi dengan sikap toleransi yang tinggi.Masalahnya keberagaman yang ada tidak dibarengi dengan sikap saling menghormati dan saling mengerti. Bahkan sikap yang diperlihatkan cenderung menganggap dirinya paling benar dan ingin menyalahkan yang lain. Hal seperti ini tentu saja meresahkan kenyamanan dan kesejahteraan masyarakat. ${ }^{1}$

Kasus ini tentu saja tidak lepas dari kurangnya perhatian masyarakat terhadap pendidikan keagamaan.Imbasnya banyak terjadi penyimpanganpenyimpangan akhlak manusia. Ditambah lagi dengan peran pemerintah yang kurang memperhatikan sistem Pendidikan Agama Islam di sekolah-sekolah yang tersebar di seluruh Indonesia. ${ }^{2}$ Akibat dari bentuk Pendidikan Agama Islam yang kurang tersistem baik justru menambah permasalahan lain dalam dunia pendidikan. $^{3}$

Sejauh ini, respon yang diberikan belum dapat membendung apalagi menghentikan laju pertumbuhan gerakan dari radikalisme tersebut. Justru ada kecenderungan terjadi peningkatan jumlah kasus terorisme tersebut. Eksistensi Islam yang dianggap radikal sesungguhnya merupakan ancaman bagi masa depan bangsa Indonesia. Islam Indonesia merupakan Islam yang dikenal dengan karakter ramah, toleran dan humanis. Dinamika dan pertumbuhan Islam di Indonesia sebelum tahun 2000an menunjukkan bahwa Islam toleran dan damai dapat hidup menyatu dengan masyarakat Indonesia. ${ }^{4}$

\footnotetext{
${ }^{1}$ Mustiqowati Ummul Fithriyah dan M.Saiful Umam, "Internalisasi Nilai-Nilai Aswaja Dalam Pendidikan Islam Sebagai Upaya Deradikalisasi Menuju Good Citizen," Prosiding Seminar Nasional Islam Moderat 1 (September 2018): 110-24.

2 Mohammad Kosim, "Pesantren dan Wacana Radikalisme," Karsa, 2006.

${ }^{3}$ Ahmad Darmadji, "Pondok Pesantren dan Deradikalisasi Islam di Indonesia," Millah 11, no. 1 (Agustus 2011): 235-52, https://doi.org/10.20885/millah.vol11.iss1.art12.

${ }^{4}$ Najib Kailani, “Kepanikasn Moral dan Dakwah Islam Populer (Membaca Fenomena 'Rohis' di Indonesia)," Analisis: Jurnal Studi Keislaman 11, no. 1 (2011): 1-16,
}

18 | At-Tarbiyat : Jurnal Pendidikan Islam, Vol. 03 No. 01 (2020) : 17-29 
Islam radikal merupakan karakteristik Islam yang tidak memiliki harapan hidup di masa depan ${ }^{5}$ karena tidak mengakui terhadap nilai-nilai kultur Indonesia, Padahal Islam realitas kultur budaya telah mengakar kuat di masyarakat setempat. Tidak jarang kelompok Islam radikal menggunakan jalan kekerasan dalam menjalankan aktivitas dan misi-misinya. ${ }^{6}$ Jalan kekerasan yang mereka tempuh akan memicu timbulnya kekerasan demi kekerasan berikutnya. Jika Islam radikal terus mengembangkan sayap ke berbagai bidang kehidupan maka kehidupan damai dan toleran akan semakin sulit untuk kita dapatkan. Belum lagi, tindakan-tindakan mereka yang mengatasnamakan jihad tentu akan mencederai citra Islam sebagai agama yang damai dan mendamaikan. ${ }^{7}$

Kian banyaknya generasi muda yang terperosok ke dalam organisasi Islam radikal nampaknya menyadarkan banyak pihak untuk segera menguatkan benteng pertahanan. Jika tidak segera diantisipasi maka benihbenih radikalisme akan semakin berkembang. ${ }^{8}$ Semakin meluasnya Islam radikal mungkin dikarenakan kurangnya kesadaran masyarakat terhadap pendidikan keagamaan yang berimplikasi pada semakin kecilnya peluang membangun harmoni sosial dalam masyarakat Indonesia yang multikultur ${ }^{9}$, Jalan kekerasan dan intoleransi akan semakin mewabah karena karakteristik Islam radikal memang semacam itu.

Banyak cara untuk mencegah berkembangnya paham radikal di Indonesia. Cara yang dilakukan seperti melalui media sosial, melalui pondok pesantren dan melalui Pendidikan Agama Islam di sekolah. ${ }^{10}$ Pendidikan Agama Islam di sekolah menjadi salah satu faktor penting dalam membasmi bentuk dari

https://doi.org/10.42042/ANALISIS.V11I1.604; Hairus \Salim, Najib Kailani, dan Nikmal Azekiyah, Politik Ruang Publik Sekolah: Negosiasi dan Kontestasi di SMUN Yogyakarta (Yogyakarta: Monograf CRCS UGM, 2011).

${ }^{5}$ Ngainun Naim, "Pengembangan Pendidikan Aswaja sebagai Strategi Deradikalisasi," Walisongo: Jurnal Penelitian Sosial Keagamaan 23, no. 1 (Juni 2015): 69-88, https://doi.org/10.21580/WS.23.1.222.

${ }^{6}$ Fithriyah dan Umam, "Internalisasi Nilai-Nilai Aswaja Dalam Pendidikan Islam Sebagai Upaya Deradikalisasi Menuju Good Citizen."

${ }^{7}$ Naim, "Pengembangan Pendidikan Aswaja sebagai Strategi Deradikalisasi."

${ }^{8}$ Naim.

${ }^{9}$ Thohir Yuli Kusmato, Moh Fauzi, dan M Mukhsin Jamil, "Dialektika Radikalisme dan Anti Radikalisme di Pesantren,” Walisongo: Jurnal Penelitian Sosial Keagamaan 23, no. 1 (Juni 2015): 27-50, https://doi.org/10.21580/WS.23.1.221.

${ }^{10}$ Tim Badan Litbang dan Diklat Kementerian Agama Republik Indonesia, Moderasi Beragama, Balibang Kemenag RI (Jakarta: Kementerian Agama RI, 2019), https://doi.org/10.1017/CBO9781107415324.004.

19 | At-Tarbiyat : Jurnal Pendidikan Islam, Vol. 03 No. 01 (2020) : 17-29 
radikslisme di Negara Kesatuan Republik Indonesia. Pendidikan juga sebagai ujung tombak Indonesia untuk membangun generasi emas yang baik. Melalui pendidikan diharapkan mampu menciptakan serta menumbuhkan akhlak serta budi pekerti. Perilaku manusia yang baik akan mengembalikan rasa hormat terhadap dirinya dan lingkungannya. Melalui pendidikan juga kita mampu menanamkan karakter terhadap generasi yang akan mendatang khususnya melalui pendidikan agama terhadap sekolah-sekolah. ${ }^{11}$

Pendidikan Agama Islam merupakan pendidikan yang identik pada pembentukan budi pekerti atau karakter.Maka dari itu pendidikan karakter dalam sistem Pendidikan Agama Islam dapat menjadi solusi atas permasalahan radikalisme.Sekolah sebagai penyelenggara pendidikan diharapkan dapat menjadi tempat yang mampu mewujudkan misi dari pembentukan karakter moderat tersebut.Diharapkan dengan pembentukan karakter yang sesuai dengan norma-norma kemanusiaan dapat mencegah atau sedikitnya mengurangi kasus radikalis.

Karakter yang moderat tidak akan terwujud hanya dengan melaksanakan kurikulum yang diberikan pemerintah begitu saja. Perlu adanya inovasi kurikulum dari sekolah.Maka dari itu tugas sekolah terutama guru Pendidikan Agama Islam adalah melakukan inovasi kurikulum.Maka dari itu penelitian ini hendak menjelaskan tentang bagaimana peran Pendidikan Agama Islam dalam deradikalisasi dan bagaimana Pendidikan Agama Islam dapat menciptakan karkter yang moderat.Penelitian ini merupakan penelitian literatur dengan mengkaji berbagai sumber yang berkaitan dengan inovasi kurikulum dan radikalisme.Sumber primer berasal dari buku-buku tantang konsep inovasi kurikulum sedangkan sumber sekunder berasal dari buku-buku tentang perkembangan paham radikalisme di sekolah-sekolah.Analisis penelitian ini menggunakan analisis isi.

${ }^{11}$ Umma Farida, "Radikalisme, Moderatisme, dan Liberalisme Pesantren: Melacak Pemikiran dan Gerakan Keagamaan Pesantren di Era Globalisasi," Edukasia : Jurnal Penelitian Pendidikan Islam 10, no. 1 (Maret 2015), https://doi.org/10.21043/edukasia.v10i1.789.

20 | At-Tarbiyat : Jurnal Pendidikan Islam, Vol. 03 No. 01 (2020) : 17-29 


\section{PEMBAHASAN}

\section{Pendidikan Agama Islam dan Deradikalisasi}

Deradikalisasi berarti mengacu pada tindakan atau tingkah laku preventif kontra terorisme atau strategi untuk menetralisir pemahaman atau pahampaham yang dianggap radikal dan membahayakan dengan cara pendekatan tanpa kekerasan. ${ }^{12}$ Tujuan dari deradikalisasi ini adalah untuk mengembalikan orang yang memiliki pemahaman radikal kembali ke jalan pemikiran yang lebih moderat. Terorisme menjadi permasalahan serius bagi dunia internasional karena setiap saat akan membahayakan keamanan nasional bagi setiap negara. Maka dari itu program deradikalisasi dibutuhkan sebagai formula penanggulangan dan pencegahan pemahaman radikal seperti terorisme.

Selain itu, deradikalisasi juga merupakan upaya mengajak masyarakat yang radikal, terutama narapidana teroris, mantan napi teroris, keluarga dan jaringannya agar kembali ke jalan yang benar berdasarkan agama, moral, dan etika yang senapas dengan esensi ajaran semua agama yang sangat mengahrgai keberagaman dan perbedaan. Program deradiklaisasi ingin mengajarkan kepada semua untuk kembali menjadi warga negara yang sesuai dengan pancasila dan UUD. $^{13}$

Pelaksanaan kurikulum 2013 mengalami kendala di lapangan berupa belum adanya buku panduan untuk pelajar yamg mengakibatkan pelajar harus aktif mencari materi pelajaran diinternet.Dengan pencarian informasi di internet tanpa saringan ideologi mengakibatkan pelajar berpotensi lebih besar bersikap radikal karena kesalahan pemahaman materi yang dicari. Maka untuk menghadapi hal tersebut diadakan upaya deradikalisasi melalui kurikulum pendidikan agama islam dalam mewujudkan pengenalan, terintegrasi dalam silabus, bahan ajar, dan RPP. ${ }^{14}$

\footnotetext{
${ }^{12}$ Daniel Koehler, Understanding Deradicalization: Methods, Tools and Programs for Countering ... - Daniel Koehler - Google Buku (New York: Routledge, 2017).

${ }^{13}$ Kisbiyanto Kisbiyanto, "Manajemen Kurikulum Dalam Perspektif Anti-Radikalisme," ADDIN 10, no. 1 (Februari 2016): 181, https://doi.org/10.21043/addin.v10i1.1134.

${ }^{14}$ Putri Hergianasari, "Konsep Deradikalisasi Pada Pendidikan Berbasis Pembelajaran Terpadu," Scholaria: Jurnal Pendidikan dan Kebudayaan 9, no. 3 (September 2019): 239-44,
}

21 | At-Tarbiyat : Jurnal Pendidikan Islam, Vol. 03 No. 01 (2020) : 17-29 
Upaya deradikalisasi melalui kurikulum yaitu berusaha mengenalkan kepada pelajar bahwa islam selalu mengajarkan kedamaian, kerukunan, ketentraman baik sasama umat islam maupun yang berbeda pemahaman ataupun berbeda agama. dengan kurikulum membentuk karakter siswa yang tidak radikal tetapi memiliki nila-nilai keagamaan yang kuat, memiliki karakter toleransi yang sangat tinggi serta memiliki karakter cinta damai dan selalu menjaga persatuan dan kesatuan bangsa indonesia. Pengembangan kurikulum pendidikan islam bukan hanya dirancang sebagai program deradikalisasai saja tetapi dirancang untuk menyongsong beberapa tahun kedepan dengan menyiapkan generasi muda yang maju dan berkembang yang memiliki kualitas yang tinggi. ${ }^{15}$

Pencegahan gerakan terorisme melalui Pendidikan Agama Islam dapat dengan mengubah struktur materi pelajaran Pendidikan Agama Islam.Misalnya memasukkan muatan materi pendidikan perdamaian dalam materi ajara Pendidikan Agama Islam yang nantinya digunakan untuk mempromosikan budaya perdamaian16, mengembangkan pengetahuan, kompetensi, sikap-sikap, dan nilai-nilai yang bertujuan untuk mengubah sikap, sifat, dan pola pikir seseorang yang menciptakan atau meningkatkan kekerasan. Program deradikalisasi bertujuan mengubah pikiran teroris agar tidak memilikisikap merasa paling benar dan menghilangkan budaya kekerasan yang dianutnya. Pendidikan perdamaian menjadi salah satu program deradikalisasi yang mengajak masyarakat yang radikal untuk memiliki sikap saling menghargai keberagaman dan perbedaan. ${ }^{17}$ Maka dari itu, muatan materi Pendidikan Agama Islam merupakan hal yang penting karena berpengaruh pada perilaku setiap individu.

https://doi.org/10.24246/j.js.2019.v9.i3.p239-244.

${ }^{15}$ Kisbiyanto, "Manajemen Kurikulum Dalam Perspektif Anti-Radikalisme."

${ }^{16}$ Ian M Haris, "Peace Education Theory," Journal of Peace Education 1, no. 1 (Maret 2004): 520, https://doi.org/10.1080/1740020032000178276.

${ }^{17}$ Raden Mas Jerry Indrawan dan Bayu Widiyanto, "Pendidikan Perdamaian Sebagai Bagian Dari Program Deradikalisasi: Sebuah Upaya Pencegahan Gerakan Terorisme," Jurnal Pertahanan \& Bela Negara 6, no. 1 (April 2016): 75, https://doi.org/10.33172/jpbh.v6i1.295.

22 | At-Tarbiyat : Jurnal Pendidikan Islam, Vol. 03 No. 01 (2020) : 17-29 
Pendidikan mengajak para pembelajarnya untuk memahami dan mengerti akar dan juga cabang dari sebuah konflik serta memahami alternatif-alternatif yang ditimbulkan. Pendidikan mendatangkan cara berpikir alternatif yang adil dan membangun upaya resolusi dan tranformasi konflik melalui cara-cara non kekerasan. Hal iniberarti bahwa proses pembelajaran harus bersifat holistik dan berusaha menyentuh dimensi kognitif, afektif, dan psikomotorik dari pembelajarnya. Mereka dapat belajar menyelesaikan masalah dengan metode collaboration problem solving, diharapkan juga dapat mengubah mindset dari para pelaku terorisme. ${ }^{18}$ Kurikulum pendidikan tidak boleh dipisahkan dari program utama karena program ini pasti berbicara bagaimana mengembangkan sifat toleransi terhadap umat beragama. Pentingnya toleransi pada program deradikalisasi dapat dilakukan dengan pembiasaan seperti halnya yang dicontohkan oleh kepemimpinan Rasullullah Saw bahwa pentingnya membangun masyarakat yang berpondasikan ketuhanan yang maha esa dan adanya toleransi beragama menjadi salah satu cara untuk mencegah kekerasan dan terorisme.

Radikalisme muncul disebabkan oleh dua faktor, yaitu faktor internal dan faktor eksternal. Radikalisasi dapat terjadi kepada siapapun dan dimanapun tak terkecuali pada pelajar di sekolah. Maka perlu dilakukan pencegahan dan penanganan secara cepat bagi penganut radikalisme.Deradikalisasi biasanya dilakukan melalui hipnoterapi, bimbingan, bimbingan agama, dan teknologi. Ini berarti peran Guru Pendidikan Agama Islam menjadi sangat sentral karenan Guru merupakan orang yang seharusnya membimbing anak didiknya agar tidak terjerumus kedalam paham yang radikal.

Maka dari itu ada dua hal pokok mengenai guru yang harus dicermati agar Pendidikan Agama Islam dapat berperan dalam deradikalisasi.Hal tersebut adalah bagaimana corak berpikir guru, apakah guru memiliki pemikiran yang luas atau sempit, toleran atau saklek, moderat atau radikal. Hal tersebut akan berpengaruh kepada corak berpikir anak didik. Selanjutnya guru merupakan

\footnotetext{
${ }^{18}$ Indrawan dan Widiyanto.
}

23 | At-Tarbiyat : Jurnal Pendidikan Islam, Vol. 03 No. 01 (2020) : 17-29 
orang membina dan membimbing anak didik. Cara membimbing yang dan membina akan mengantarkan anak didik untuk mengikuti paham yang dianut gurunya. Jika guru mengikuti organisasi yang ekstrim maka dimungkinkan hal tersebut akan diikuti oleh anak didiknya.

Analisis diatas dapat memberikan gambaran bahwa Pendidikan Agama Islam dapat berperan dengan melihat akar masalah radikalisai yang terjadi. Pendidikan Agama Islam dapat melakukan proses deradikalisasi. Pendidikan Agama Islam dapat melakukan tindakan pada tiga ranah yaitu melakukan pengembangan materi ajar, membentuk corak berpikir guru dan mengawasi peserta didik dengan cara membina dan membimbing kegiatan keagamaan.

\section{Pembentukan Karakter Moderat}

Kurikulum merupakan salah satu syarat mutlak serta bagian yang tidak dapat dipisahkan dari pendidikan. Kurikulum memiliki kedudukan dan posisi yang sangat strategis dalam segala keseluruhan proses pendidikan. Kurikulum juga berisi tentang bagaimana mengembangkan seluruh potensi yang dimiliki oleh pelajar sehingga dapat berkembang secara maksimal dan dapat menciptakan lulusan yang berkualitas dan mampu bersaing didunia luas seperti dikancah MEA. ${ }^{19}$

Salah satu upaya strategis dalam langkah membentuk lulusan yang berkualitas dan mampu bersaing dikacah MEA yaitu dengan mengembangkan kurikulum yang ada, terlebih pada kurikulum pendidikan agama islam. Pengembangan kurikulum pendidikan islam berisi tentang hal-hal yang dapat membantu menciptakan SDM (Sumber Daya Manusia) yang memiliki ketrampilan dan daya saing yang tinggi. Di dalam kurikulum pendidikan islam juga mencakup pendidikan yang dapat meningkatkan kecakapan berbahasa bagi lulusan sehingga dapat berperan aktif dalam dunia kerja internasional khususnya di ASEAN. Kurikulum juga harus memperhatikan arus teknologi dan

\footnotetext{
${ }^{19}$ Muhammad Tisna Nugraha, "Pengembangan Model Kurikulum Pendidikan Agama Islam (PAI) Menuju Masyarakat Ekonomi Asean (MEA) Muhamad Tisna Nugraha," At-Turats: Jurnal Pemikiran Pendidikan Islam 10, no. 1 (2016): 13-21.
}

24 | At-Tarbiyat : Jurnal Pendidikan Islam, Vol. 03 No. 01 (2020) : 17-29 
budaya secara global agar lulusan tidak kehilangan jati diri dan identitas budaya bangsa. $^{20}$

Berdasarkan uraian diatas pengembangan kurikulum seharusnya mengalami perubahan untuk menghadapi persoalan yang terjadi. Salah satu model kurikulum yang ditawarkan ialah pendekatan the grass root model model pengembangan ini bersumber dari guru atau dosen untuk pengembangan kurikulum. Hal ini berdasarkan pada pengetahuan guru karena guru yang lebih mengetahui kondisi dan kebutuhan yang diperlukan oleh peserta didik. Pengembangan kurikulum memungkinkan terjadinya kompetisi dalam meningkatkan mutu dan sistem pendidikan sehingga dapat menjawab persolan yag dihadapi.

Deradikalisasaai (berbasis) pendidikan islammoderat dapat dijalankan dengan baik, apabila ditopang dengan konsepsi yang kokoh, sinergitas antarinstitusi, dan perumusan kebijakan radikalisme yang membumi dalam arti lebih berbasis bukti-bukti real dilapangan. Berawal dari konsep al Quran yang menganjurkan seseorang berperilaku moderat lalu diturunkan menjadi aspek tindakan. Aspek tindakan ini memiliki berbagai cara sepertipendekatan penanaman nilai, pendekatan moral kognitif, pendekatan analisis dan klarifikasi nilai dan pendekatan partisipatif action. ${ }^{21}$ Beberapa komponen penting pendidikan islam perlu direkontruksi agar dapat selaras dengan visi deradikalisasi itu sendiri, utamanya adalah komponen kurikulum, pendidik, dan strategi pembelajaran. ${ }^{22}$

Pertama perumusan kurikulum pendidikan islam bermuatan nilai-nilai toleransi ditengah-tengah semakin meningkatnya konflik kekerasan sosial keagamaan. Kurikulum ini nantinya akan menjadi pedoman bagi para pendidik dalam menyampaiakan materi-materi ajaran islam yang menghargai keragaman dan perbedaan. Materi pelajaran yang lebih banyak bersifat normatif-doktrinal-

\footnotetext{
${ }^{20}$ Muhamad Tisna Nugraha, "Fundametalisme Pendidikan Agama di Jejaring Sosial," Al-Tahrir: Jurnal Pemikiran Islam 18, no. 1 (2018), https://doi.org/10.21154/altahrir.v18i1.1172.

${ }^{21}$ Ashif Az Zafi, "Penerapan Nilai-nilai Moderasi al-Qur'an dalam Pendidikan Islam," Jurnal Studi Ilmu-ilmu Al-Qur'an dan Hadis 21, no. 1 (Januari 2020), https://doi.org/10.14421/QH.2020.\%X.

${ }^{22}$ Mohammad Rapik, "Deradikalisasi Faham Keagamaan Sudut Pandang Islam,” onlinejournal.unja.ac.id, 2014.
}

25 | At-Tarbiyat : Jurnal Pendidikan Islam, Vol. 03 No. 01 (2020) : 17-29 
deduktif harus diintegrasikan juga dengan materi-materi yang bersifat historisempiris-induktif.Dalam hal ini dibutuhkan pertimbangan antara materi yang berdimensi "teks" dan reaalitas empiris-faktual yang berdimensi "konteks".

Adapun tindakan yang lain untuk pencegahan radikalisasi melalui pendidikan formal pelatihan dan konseling. Upaya yang dilakukan untuk mencegah hal tersebut dikalangan pelajar salah satunya dengan cara mengenalkan pendidikan islam kepada pelajar juga menanamkan nilai nasionalisme ${ }^{23}$ pada diri pelajar yang dapat dimasukkan kedalam kurikulum pembelajar. $^{24}$

Kedua, hadirnya sosok pendidik yang berparadigma inklusifmultikulturalperlu sekali ditekankan dalam proses pembelajaran agama disekolah. Seorang guru ataupun dosen yang mempunyai paradigma pemahaman dan keberagaman inklusif dan moderat akan mampu mengajarkan sekaligus mengaktualisasikan nilai-nilai tersebut kepada peserta didiknya. ${ }^{25}$

Ketiga, kreativitas pendidika untuk mendesain serta menggunakan strategi pembelajaran yang tepat, sehingga hal itu kemudian memotivasi peserta didik untuk mengaktualisasikan nilai-nilai toleransi dalam kehidupan seharihari. Dalam hal ini yang sangat diperlukan adalah strategi pembelajaran yang lebih variatif, tidak parsial, dan tidak mengedapankan pendekatan kualitatif.

\section{KESIMPULAN}

Banyaknya fenomena tentang radikalisme yang terjadi saat ini menimbulkan persoalan yang membuat resah dan perlu penanganan yang serius. Fenomena tentang radikalisasi dapat terjadi pada siapa saja dan dimana saja tidak terkecuali di dalam pendidikan. Untuk menghadapi persoalan tersebut perlu adanya pengembangan kurikulum sebagai program

${ }^{23}$ Ashif Az Zafi, "Nilai Nasionalisme Kebangsaan Aktivis Rohis," BELAJEA: Jurnal Pendidikan Islam 4, no. 2 (Desember 2019), https://doi.org/10.29240/belajea.v4i2.861.

${ }^{24}$ M. Zaki Mubarak, Zulkifli Zulkifli, dan Iim Halimatussa'diyah, "Kebijakan Deradikalisasi di Perguruan Tinggi: Studi Tentang Efektifitas Kebijakan Perguruan Tinggi Dalam Mencegah Perkembangan Paham Keagamaan Radikal di Kalangan Mahasiswa (Studi Kasus UI, UGM dan UIN Maulana Malik Ibrahim Malang)," Istiqro 16, no. 01 (2018): 1-28.

${ }^{25}$ Naim, "Pengembangan Pendidikan Aswaja sebagai Strategi Deradikalisasi." 
deradikalisasi.Kesimpulan penelitian ini adalah pertama, Pendidikan Agama Islam dapat berperan dalam deradikalisasi melalui muatan materi, corak berpikir Guru dan pembinaan guru terhadap siswa. Kedua, inovasi kurikulum untuk membentuk karakter moderat yang dapat dilakukan dengan cara memberikan muatan nilai toleransi dan cinta tanah air, menciptakan guru yang berparadigma inklusif, melaksanakan pembelajaran dengan kreatif dan aktual. 


\section{DAFTAR PUSTAKA}

Darmadji, A. (2011). Pondok Pesantren dan Deradikalisasi Islam di Indonesia. Millah, 11(1), 235-252. https:/ / doi.org/10.20885/millah.vol11.iss1.art12

Farida, U. (2015). Radikalisme, Moderatisme, dan Liberalisme Pesantren: Melacak Pemikiran dan Gerakan Keagamaan Pesantren di Era Globalisasi. Edukasia : Jurnal Penelitian Pendidikan Islam, 10(1). https:// doi.org/10.21043/edukasia.v10i1.789

Fithriyah, M. U., \& Umam, M. S. (2018). Internalisasi Nilai-Nilai Aswaja Dalam Pendidikan Islam Sebagai Upaya Deradikalisasi Menuju Good Citizen. Prosiding Seminar Nasional Islam Moderat, 1, 110-124. https:// ejournal.unwaha.ac.id/index.php/asdanu/article/view/239

Haris, I. M. (2004). Peace Education Theory. Journal of Peace Education, 1(1), 5 20. https:// doi.org/10.1080/1740020032000178276

Hergianasari, P. (2019). Konsep Deradikalisasi Pada Pendidikan Berbasis Pembelajaran Terpadu. Scholaria: Jurnal Pendidikan Dan Kebudayaan, 9(3), 239-244. https://doi.org/10.24246/j.js.2019.v9.i3.p239-244

Indonesia, T. B. L. dan D. K. A. R. (2019). Moderasi Beragama. In Balibang Kemenag RI. Kementerian Agama RI. https:// doi.org/10.1017/CBO9781107415324.004

Indrawan, R. M. J., \& Widiyanto, B. (2016). Pendidikan Perdamaian Sebagai Bagian Dari Program Deradikalisasi: Sebuah Upaya Pencegahan Gerakan Terorisme. Jurnal Pertahanan \& Bela Negara, 6(1), 75. https:// doi.org/10.33172/jpbh.v6i1.295

Kailani, N. (2011). Kepanikasn Moral dan Dakwah Islam Populer (Membaca Fenomena 'Rohis' di Indonesia). Analisis: Jurnal Studi Keislaman, 11(1), 1-16. https:/ / doi.org/10.42042/ ANALISIS.V11I1.604

Kisbiyanto, K. (2016). Manajemen Kurikulum Dalam Perspektif Anti$\begin{array}{lll}\text { Radikalisme. } & \text { ADDIN, } & 181 \text { (1), }\end{array}$ https:// doi.org/10.21043/addin.v10i1.1134

Koehler, D. (2017). Understanding Deradicalization: Methods, Tools and Programs for Countering ... - Daniel Koehler - Google Buku. Routledge. https://books.google.co.id/books?hl=id\&lr=\&id=_CwlDwAAQBAJ\&oi $=$ fnd $\& \mathrm{pg}=\mathrm{PP} 1 \& \mathrm{dq}=$ deradicalisation\&ots $=-$

JLTqk2Rmc\&sig=UgKj80qxFfrmcU9Dw2uv5EWGaeU\&redir_esc $=\mathrm{y} \#_{\mathrm{v}}=\mathrm{o}$ nepage \&q=deradicalisation $\& \mathrm{f}=$ false 
Kosim, M. (2006). Pesantren dan Wacana Radikalisme. Karsa. http:/ /id.portalgaruda.org/ ?ref=browse\&mod=viewarticle\&article=251 126

Mubarak, M. Z., Zulkifli, Z., \& Halimatussa'diyah, I. (2018). Kebijakan Deradikalisasi di Perguruan Tinggi: Studi Tentang Efektifitas Kebijakan Perguruan Tinggi Dalam Mencegah Perkembangan Paham Keagamaan Radikal di Kalangan Mahasiswa (Studi Kasus UI, UGM dan UIN Maulana Malik Ibrahim Malang). Istiqro, 16(01), 1-28. http:/ / www.detiknews.com/read/2011/04/29/101430/1628335/10/uiakan-

Naim, N. (2015). Pengembangan Pendidikan Aswaja sebagai Strategi Deradikalisasi. Walisongo: Jurnal Penelitian Sosial Keagamaan, 23(1), 6988. https:// doi.org/10.21580/WS.23.1.222

Nugraha, Muhamad Tisna. (2018). Fundametalisme Pendidikan Agama di Jejaring Sosial. Al-Tahrir: Jurnal Pemikiran Islam, 18(1). https:// doi.org/10.21154/altahrir.v18i1.1172

Nugraha, Muhammad Tisna. (2016). Pengembangan Model Kurikulum Pendidikan Agama Islam (PAI) Menuju Masyarakat Ekonomi Asean (MEA) Muhamad Tisna Nugraha. At-Turats: Jurnal Pemikiran Pendidikan Islam, 10(1), 13-21. http://jurnaliainpontianak.or.id/index.php/atturats

Rapik, M. (2014). Deradikalisasi Faham Keagamaan Sudut Pandang Islam. Online-Journal.Unja.Ac.Id. http://onlinejournal.unja.ac.id/index.php/jimih/article/view/2063/1408

Salim, H., Kailani, N., \& Azekiyah, N. (2011). Politik Ruang Publik Sekolah: Negosiasi dan Kontestasi di SMUN Yogyakarta. Monograf CRCS UGM.

Yuli Kusmato, T., Fauzi, M., \& Mukhsin Jamil, M. (2015). Dialektika Radikalisme dan Anti Radikalisme di Pesantren. Walisongo: Jurnal Penelitian Sosial Keagamaan, 23(1), 27-50. https:/ / doi.org/10.21580/WS.23.1.221

Zafi, A. A. (2019). Nilai Nasionalisme Kebangsaan Aktivis Rohis. BELAJEA: Jurnal Pendidikan Islam, 4(2). https:/ / doi.org/10.29240/ belajea.v4i2.861

Zafi, A. A. (2020). Penerapan Nilai-nilai Moderasi al-Qur'an dalam Pendidikan Islam. Jurnal Studi Ilmu-Ilmu Al-Qur'an Dan Hadis, 21(1). https:// doi.org/10.14421/QH.2020.\%X 